Supplement of Hydrol. Earth Syst. Sci., 20, 2063-2083, 2016

http://www.hydrol-earth-syst-sci.net/20/2063/2016/

doi:10.5194/hess-20-2063-2016-supplement

(C) Author(s) 2016. CC Attribution 3.0 License.

(c) (1)

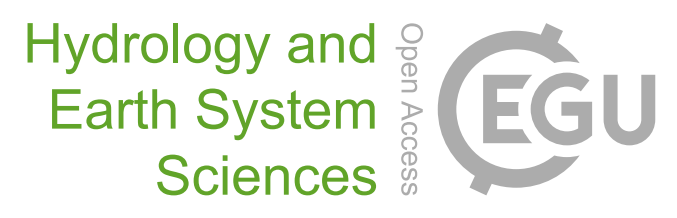

Supplement of

\title{
Dominant controls of transpiration along a hillslope transect inferred from ecohydrological measurements and thermodynamic limits
}

Maik Renner et al.

Correspondence to: Maik Renner (mrenner@bgc-jena.mpg.de)

The copyright of individual parts of the supplement might differ from the CC-BY 3.0 licence. 


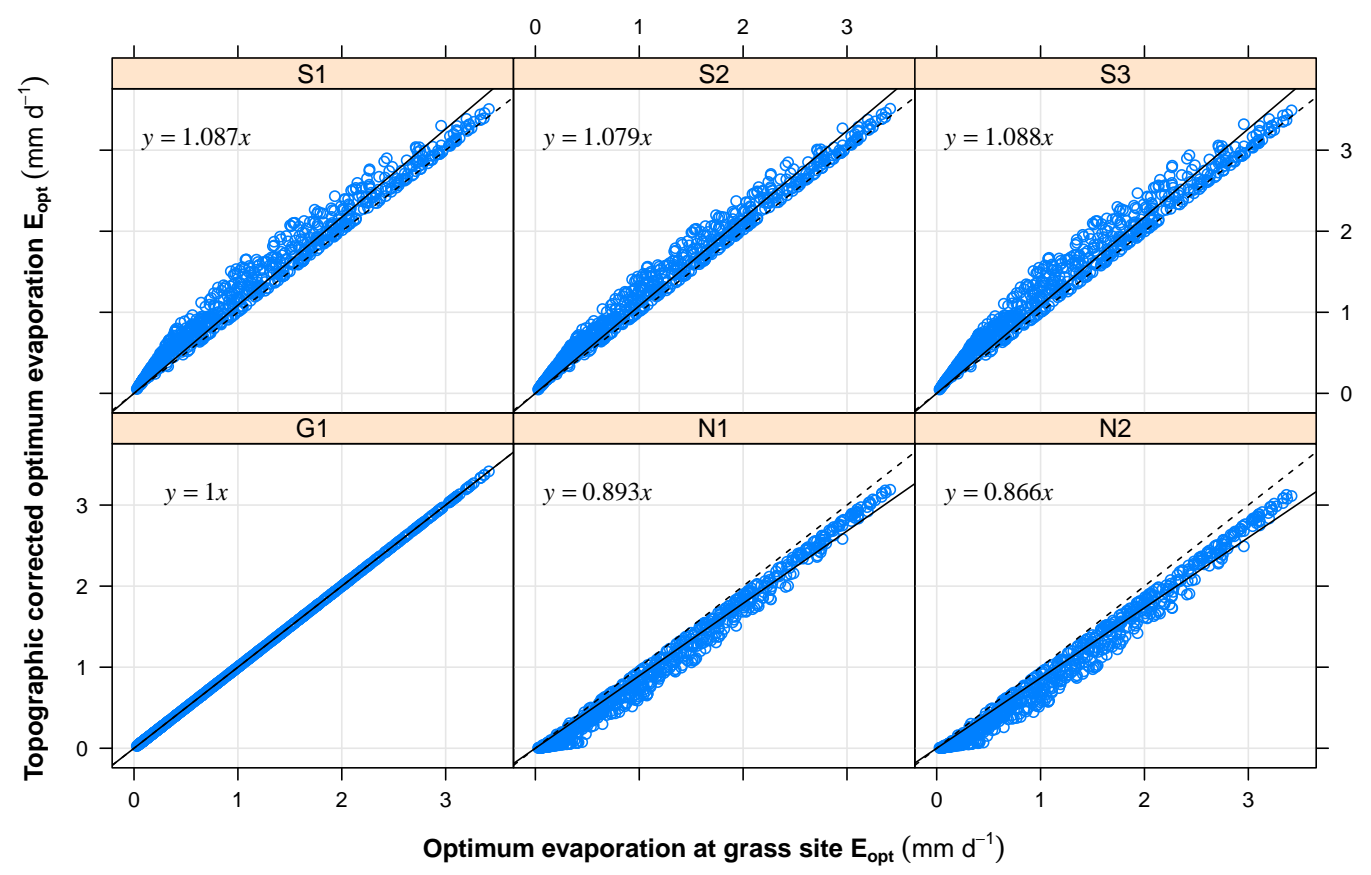

Figure S1: Comparison of daily values of optimum evaporation for all sites. x-axis $E_{\text {opt }}$ with radiation at grass site. y-axis $E_{\text {opt }}$ estimated from topographically altered radiation (aspect, slope, shading via r.sun). 


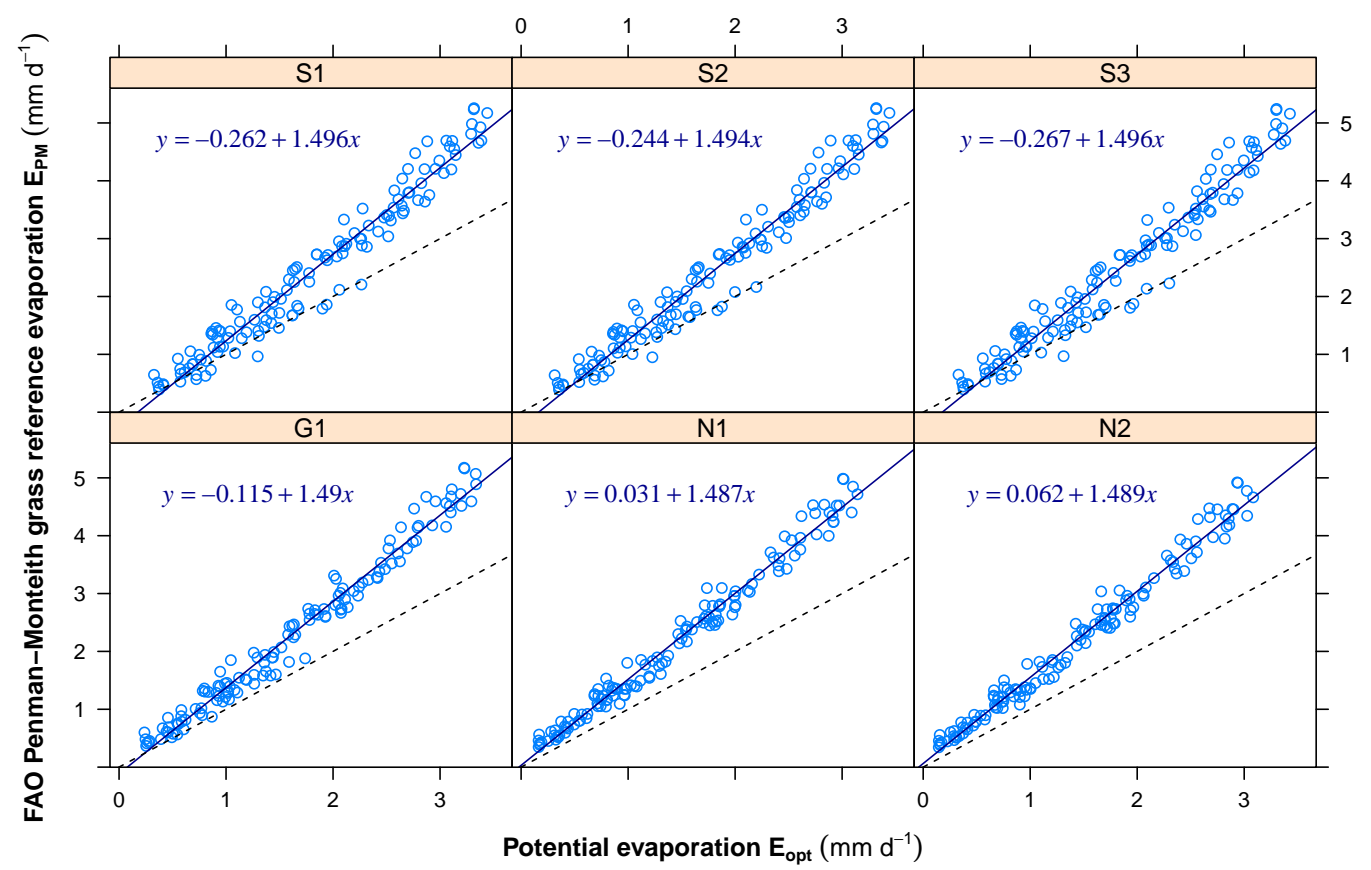

Figure S2: Comparison of potential evaporation estimates for vegetation period in 2013 for each site. The FAO Penman-Monteith grass reference evaporation is plotted as a function of $E_{\text {opt }}$. 

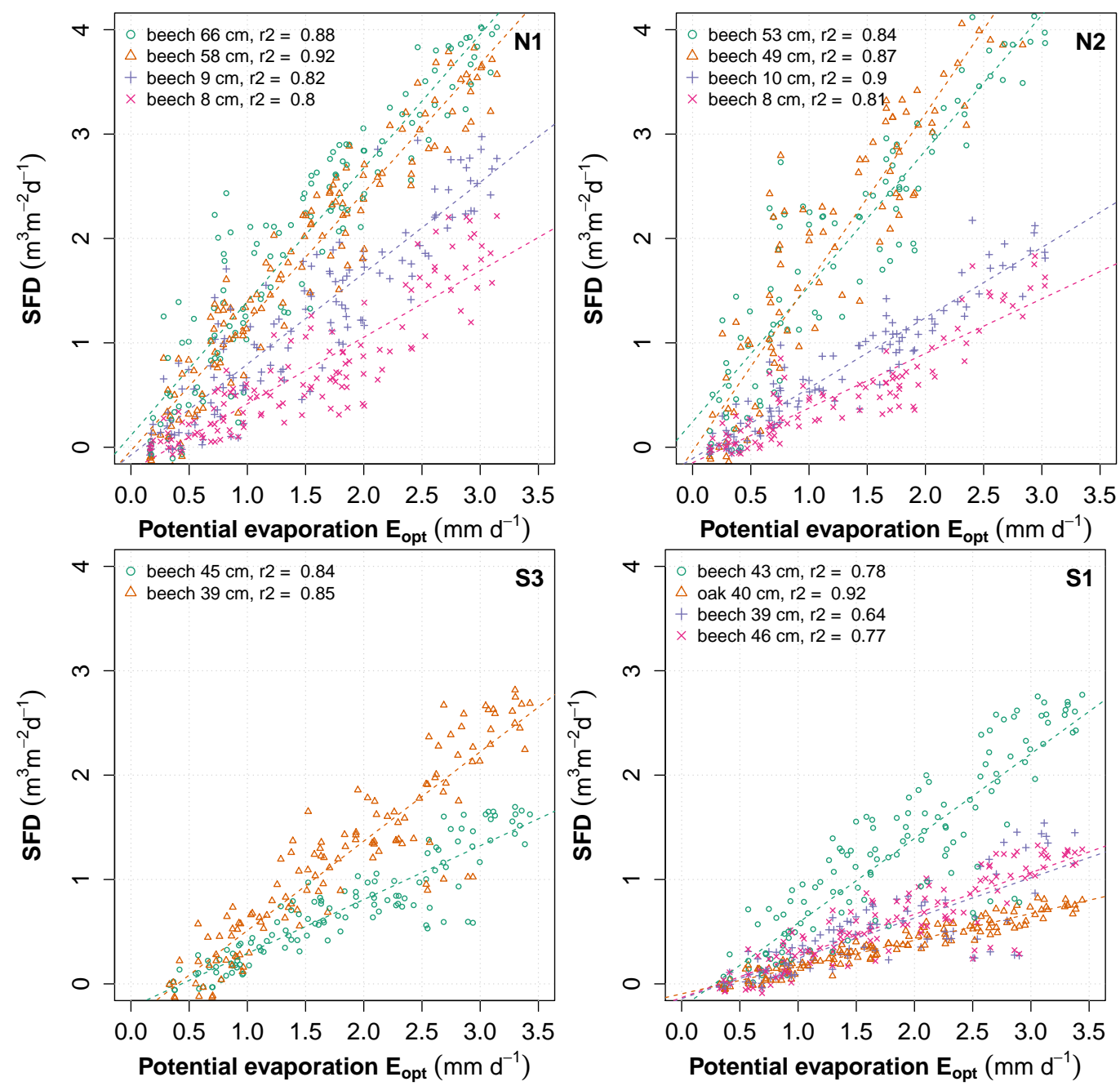

Figure S3: Daily tree average sap flux density as function of site-average $E_{\text {opt }}$ at four sites (per panel) during the vegetation period (10.June - 20.October) in 2013. Colors and symbols depict different trees. The dashed lines depicts the linear regression line reported in Table 3 of the main text. 
Table S1: Depth below surface in cm of installed soil moisture sensors.

\begin{tabular}{lrllll}
\hline site & pid & $(0,20]$ & $(20,40]$ & $(40,60]$ & $(60,80]$ \\
\hline $\mathrm{G} 1$ & 1 & 7 & 27 & 50 & \\
$\mathrm{G} 1$ & 2 & 10 & 30 & 55 & \\
$\mathrm{G} 1$ & 3 & 10 & 29 & 50,60 & \\
$\mathrm{~N} 1$ & 1 & 10 & 30 & 50 & \\
$\mathrm{~N} 1$ & 2 & 10 & 30 & 50 & 70 \\
$\mathrm{~N} 1$ & 3 & 10 & 30 & 50 & \\
$\mathrm{~N} 2$ & 1 & 10 & 30 & 50 & \\
$\mathrm{~N} 2$ & 2 & 10 & 30 & 50 & \\
$\mathrm{~N} 2$ & 3 & 10 & 30 & 50 & \\
$\mathrm{~S} 1$ & 1 & 10 & 30 & 50 & \\
$\mathrm{~S} 1$ & 2 & 10 & 30 & 50 & \\
$\mathrm{~S} 1$ & 3 & 10 & 30 & 50 & 77 \\
$\mathrm{~S} 2$ & 1 & 10 & 33 & 50 & 65 \\
$\mathrm{~S} 2$ & 2 & 10 & 30 & 45 & \\
$\mathrm{~S} 2$ & 3 & 10 & 30 & 50 & \\
$\mathrm{~S} 3$ & 1 & 10 & 30 & 44 & \\
$\mathrm{~S} 3$ & 2 & 10 & 35 & 50 & \\
S3 & 3 & 10 & 30 & 50,58 & \\
\hline
\end{tabular}


Table S2: Number of days retained by the filter criteria for root water uptake at the soil moisture sensor level for the growing season 2013. In bracket is the number of days with complete measurements of soil moisture. Blank cells refer to no / broken sensors.

\begin{tabular}{lrllll}
\hline site & pid & $(0,20]$ & $(20,40]$ & $(40,60]$ & $(60,80]$ \\
\hline G1 & 1 & $25(133)$ & $43(133)$ & $40(133)$ & \\
G1 & 2 & $22(133)$ & $30(118)$ & $40(133)$ & \\
G1 & 3 & & $42(133)$ & $42(133)$ & \\
N1 & 1 & $35(133)$ & $39(133)$ & $38(133)$ & \\
N1 & 2 & $0(0)$ & $40(133)$ & $40(133)$ & $44(133)$ \\
N1 & 3 & $42(133)$ & $37(133)$ & $44(133)$ & \\
N2 & 1 & $41(132)$ & $41(132)$ & $41(132)$ & \\
N2 & 2 & $0(0)$ & $31(112)$ & $44(132)$ & \\
N2 & 3 & $40(132)$ & $40(132)$ & & \\
S1 & 1 & $27(133)$ & $40(133)$ & $43(133)$ & \\
S1 & 2 & $0(0)$ & $40(133)$ & $43(133)$ & \\
S1 & 3 & $5(11)$ & $44(133)$ & $44(133)$ & $44(133)$ \\
S2 & 1 & $32(112)$ & $32(112)$ & $34(112)$ & $35(112)$ \\
S2 & 2 & $24(112)$ & $34(92)$ & $34(112)$ & \\
S2 & 3 & $31(112)$ & $34(112)$ & $35(112)$ & \\
S3 & 1 & $38(133)$ & $42(133)$ & & \\
S3 & 2 & $35(133)$ & $42(133)$ & & \\
S3 & 3 & $37(133)$ & $31(133)$ & $33(94)$ & \\
\hline
\end{tabular}


Table S3: Regression statistics of $E_{R W U}$ as dependent variable and $E_{\text {opt }}$ as independent variable. Data for each soil profile (pid) per site and during the growing season of 2013. $z_{\max }$ reports depth of the deepest sensor. $b_{R W U}$ is the slope of the linear regression with $\pm \sigma$ reporting the estimated standard deviation of the coefficient. $r^{2}$ is the linear squared correlation. The last three columns report the adjusted explained variance of a linear regression of the residuals of sap flux density to $E_{\text {opt }}$ for the variables daily site-average volumetric water content $\left(R_{\theta}^{2}\right)$, daily average vapor pressure deficit $\left(R_{V P D}^{2}\right)$, and daily average windspeed $\left(R_{u}^{2}\right)$.

\begin{tabular}{lrrrllllll}
\hline site & pid & $z_{\max }$ & $\mathrm{n}$ & $b_{R W U}$ & intercept & $r^{2}$ & $R_{V P D}^{2}$ & $R_{u}^{2}$ & $R_{\theta}^{2}$ \\
\hline $\mathrm{N} 1$ & 1 & 50 & 26 & $0.62 \pm 0.18^{* *}$ & $0.52 \pm 0.33$ & 0.36 & 0.01 & -0.04 & $0.36^{* *}$ \\
$\mathrm{~N} 1$ & 2 & 70 & 35 & $0.92 \pm 0.17^{* * *}$ & $0.21 \pm 0.30$ & 0.42 & $0.05^{* *}$ & $0.09^{*}$ & $0.55^{* * *}$ \\
$\mathrm{~N} 1$ & 3 & 50 & 36 & $0.68 \pm 0.14^{* * *}$ & $-0.03 \pm 0.20$ & 0.60 & 0.03 & 0.03 & $0.50^{* * *}$ \\
\hline $\mathrm{N} 2$ & 1 & 50 & 36 & $1.17 \pm 0.20^{* * *}$ & $-0.04 \pm 0.48$ & 0.69 & -0.02 & 0.04 & 0.24 \\
$\mathrm{~N} 2$ & 2 & 50 & 0 & & & & & & \\
$\mathrm{~N} 2$ & 3 & 50 & 35 & $0.35 \pm 0.12^{* *}$ & $0.46 \pm 0.17^{*}$ & 0.34 & -0.03 & -0.02 & -0.03 \\
\hline $\mathrm{S} 3$ & 1 & 44 & 37 & $0.48 \pm 0.12^{* * *}$ & $-0.14 \pm 0.19$ & 0.30 & $0.03^{* *}$ & 0.13 & $0.62^{* * *}$ \\
$\mathrm{~S} 3$ & 2 & 50 & 33 & $0.33 \pm 0.06^{* * *}$ & $0.07 \pm 0.18$ & 0.39 & -0.03 & 0.06 & $0.56^{* * *}$ \\
$\mathrm{~S} 3$ & 3 & 58 & 25 & $0.97 \pm 0.37^{*}$ & $-0.69 \pm 0.57$ & 0.45 & -0.04 & $0.29 *$ & $0.32^{* *}$ \\
\hline $\mathrm{S} 2$ & 1 & 65 & 26 & $0.70 \pm 0.07^{* * *}$ & $-0.25 \pm 0.15$ & 0.69 & -0.00 & -0.02 & -0.01 \\
$\mathrm{~S} 2$ & 2 & 45 & 22 & $0.34 \pm 0.15^{*}$ & $0.49 \pm 0.14^{* *}$ & 0.22 & -0.02 & 0.01 & 0.46 \\
$\mathrm{~S} 2$ & 3 & 50 & 28 & $0.36 \pm 0.15^{*}$ & $0.49 \pm 0.54$ & 0.19 & -0.02 & 0.12 & $0.56^{*}$ \\
\hline $\mathrm{S} 1$ & 1 & 50 & 24 & $0.59 \pm 0.05^{* * *}$ & $-0.29 \pm 0.13^{*}$ & 0.73 & -0.05 & 0.01 & $0.35^{* *}$ \\
$\mathrm{~S} 1$ & 2 & 50 & 38 & $0.24 \pm 0.05^{* * *}$ & $0.56 \pm 0.17^{* *}$ & 0.20 & -0.03 & $0.10 * *$ & 0.03 \\
$\mathrm{~S} 1$ & 3 & 77 & 43 & $0.51 \pm 0.04^{* * *}$ & $0.04 \pm 0.07$ & 0.73 & 0.01 & 0.00 & -0.01 \\
\hline $\mathrm{G} 1$ & 1 & 50 & 24 & $0.73 \pm 0.33^{*}$ & $0.48 \pm 1.01$ & 0.29 & -0.05 & -0.04 & $0.71^{* * *}$ \\
$\mathrm{G} 1$ & 2 & 55 & 15 & $0.15 \pm 0.48^{* *}$ & $1.81 \pm 1.29$ & 0.00 & $0.06 *$ & -0.07 & $0.72^{* * *}$ \\
$\mathrm{G} 1$ & 3 & 60 & 0 & & & & & & \\
\hline
\end{tabular}




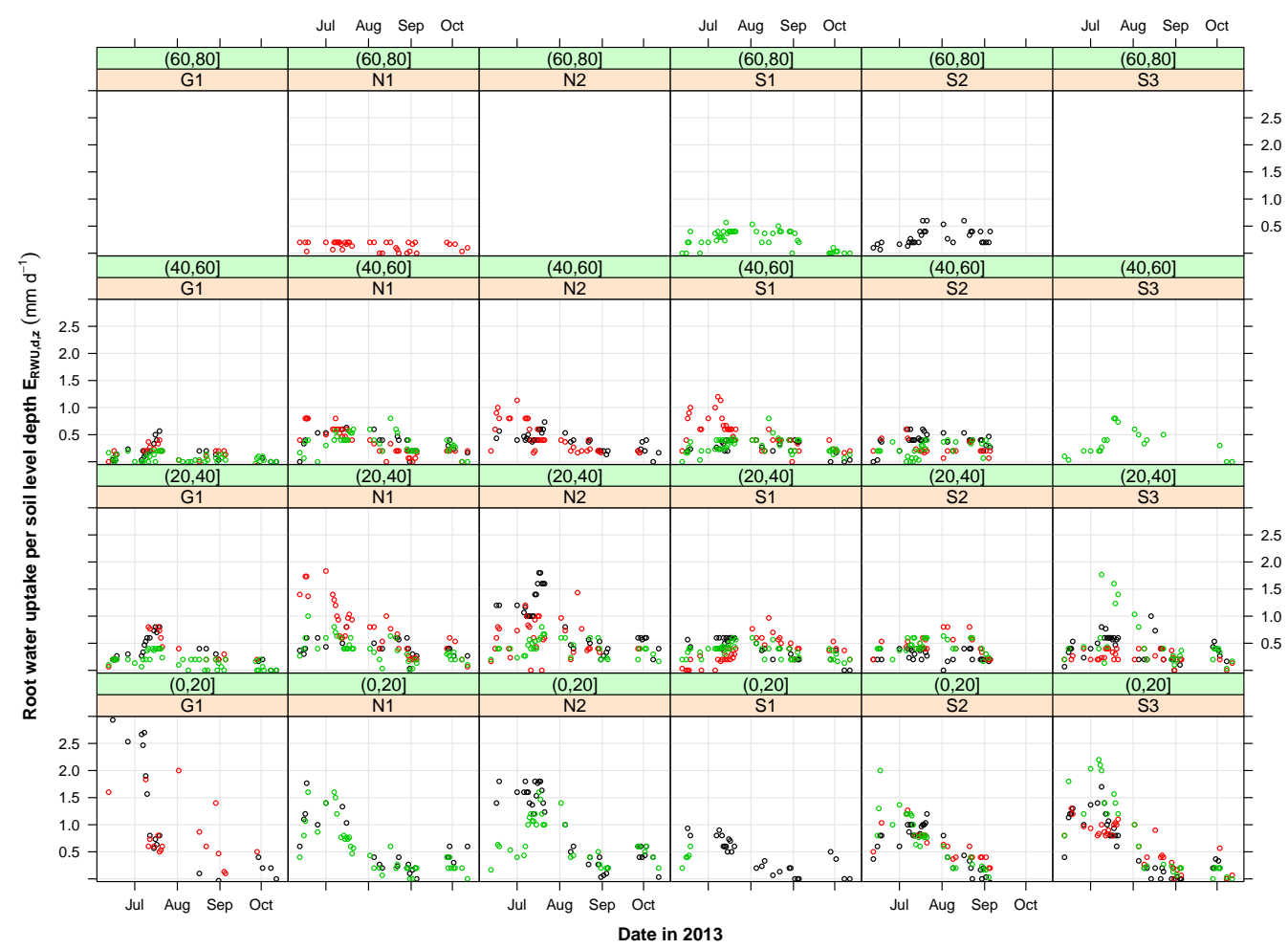

Figure S4: Estimated daily root water uptake per site and representative soil level (indicated by the header of each panel in $\mathrm{cm}$ below surface) of each soil moisture sensor for the growing season 2013. Colors represent the three different soil profiles per site. 

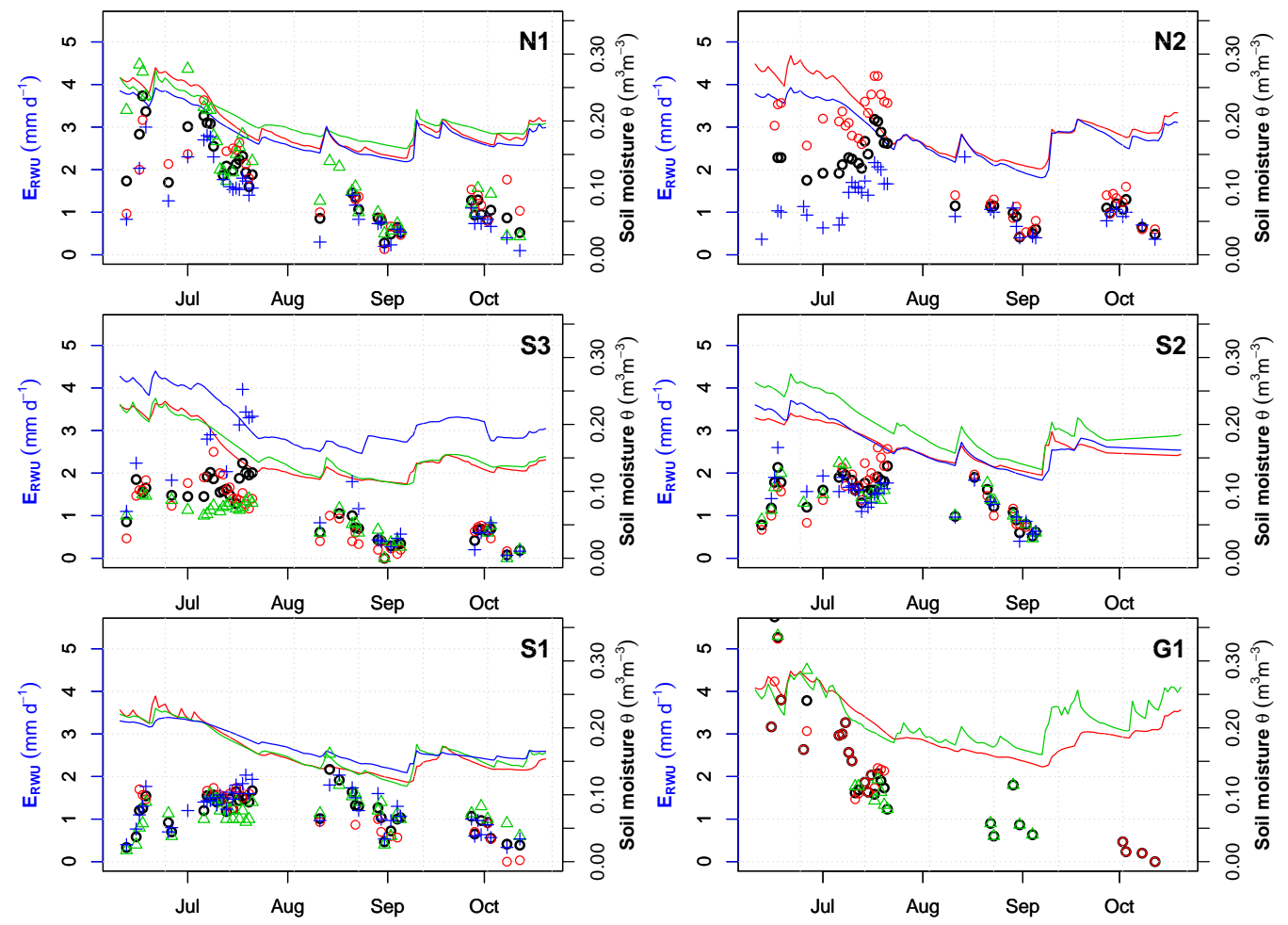

Figure S5: Time series of estimated root water uptake per profile (color coding) and the respective site-average (bold points). Profile average soil moisture is shown with axis on the right. 


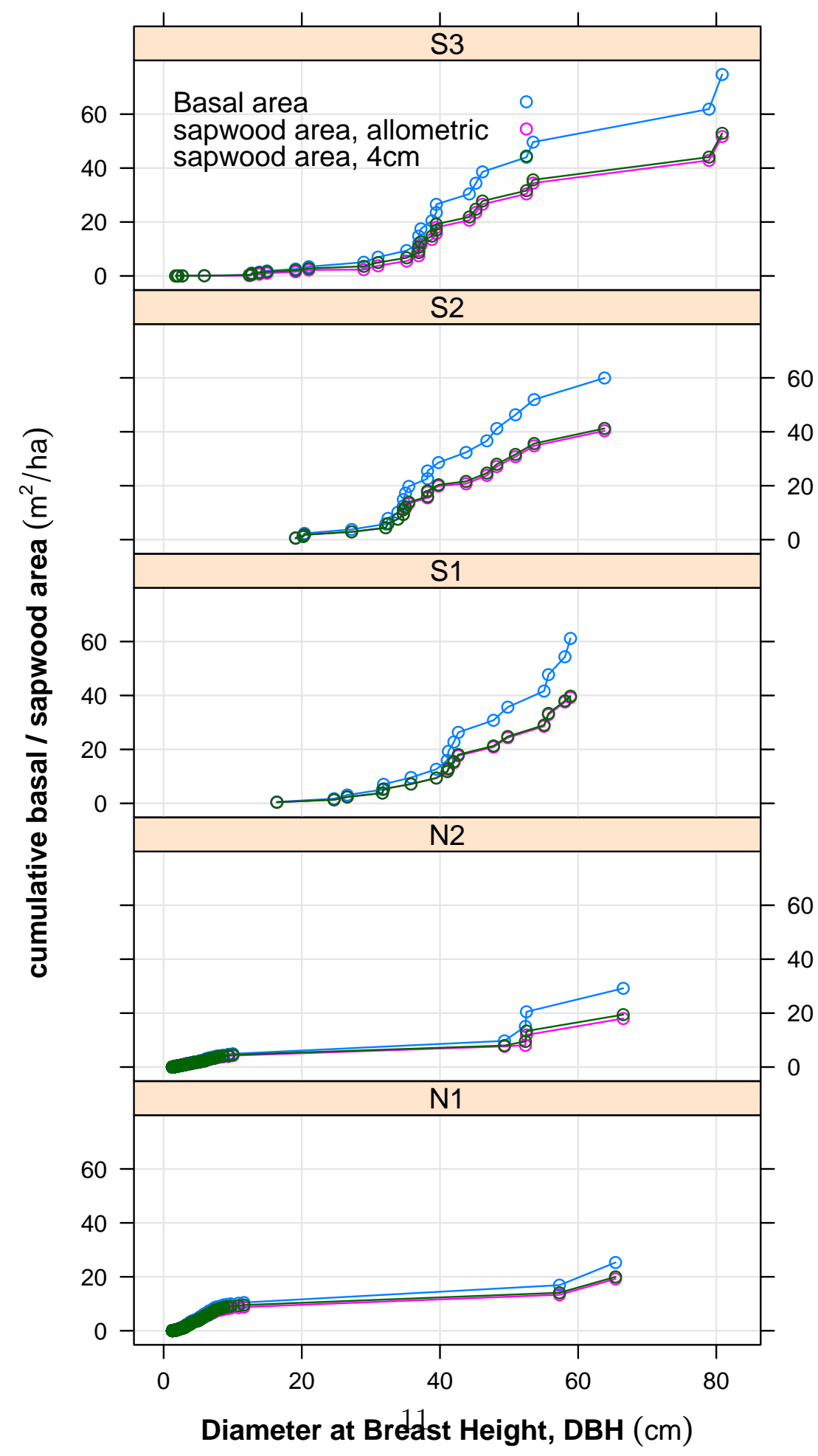

Figure S6: Cumulative distribution of basal area $A_{b}$ and sapwood area $A_{s}$ as a function of DBH for each site. Data is from the forest inventory explained in the main text section 2.5. Sapwood area is derived from species-specific allometric relationships (red) and for comparison with a fixed maximum depth of $4 \mathrm{~cm}$ (green). 

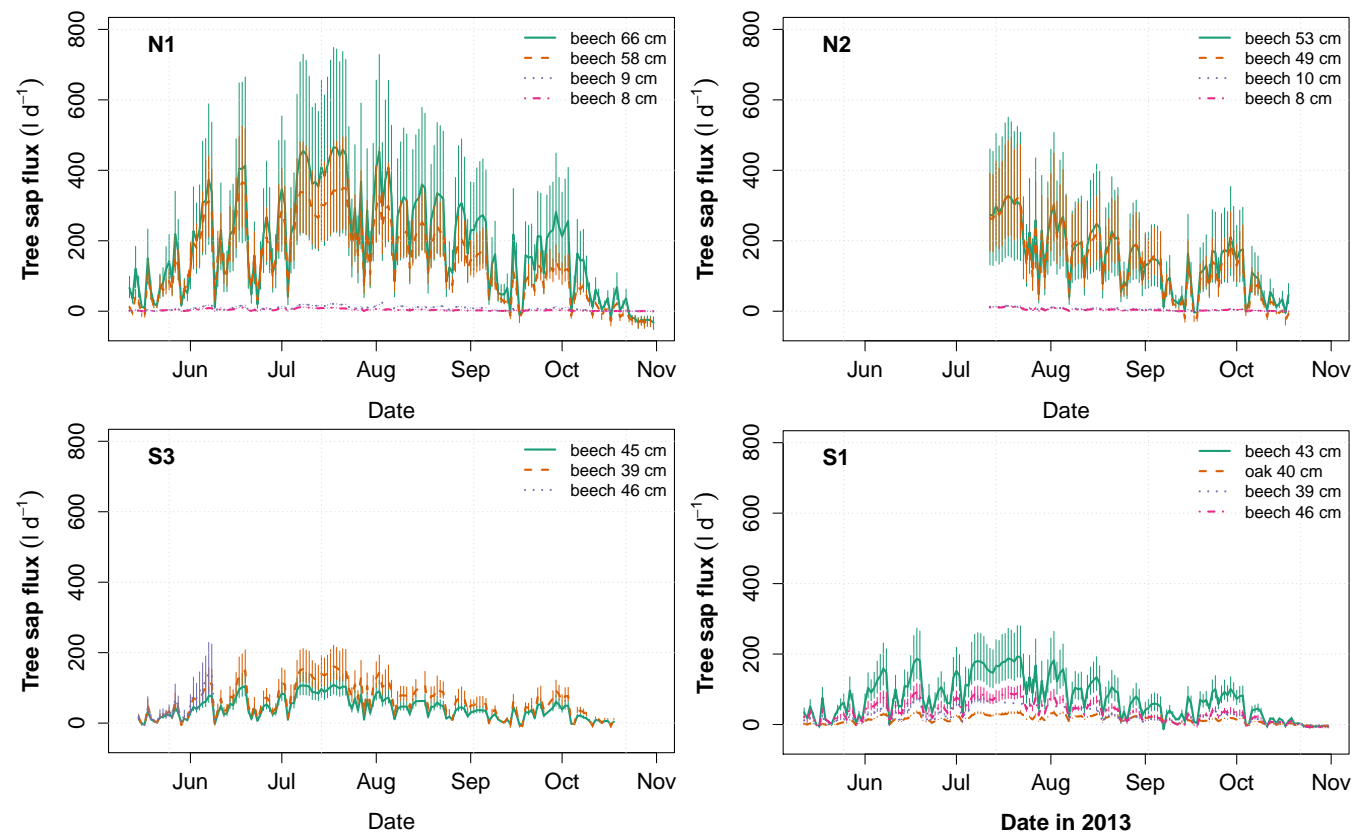

Figure S7: Daily tree-based sap flux rates for each tree (color coded) for the growing season in 2013 at site N1, N2, S3 and S1. Sap flux was obtained by integrating the product of measured $S F D$ and the representative area of each reading at a sensor depth. The bold lines represent a linear decline of $S F D$ towards the estimated heartwood radius. The thin vertical lines represent the minimal and maximal sap flux density profiles in the inner sapwood, see main text section 2.6 